\title{
Optimization and validation of a HPLC method for simultaneous determination of aflatoxin B1, B2, G1, G2, ochratoxin A, and zearalenone using experimental design.
}

\begin{abstract}
A reversed-phase HPLC optimization strategy is presented for investigating the separation and retention behavior of aflatoxin B 1, B 2, G 1, G 2, ochratoxin A and zearalenone, simultaneously. A fractional factorial design (FFD) was used to screen the significance effect of seven independent variables on chromatographic responses. The independent variables used were: $(\mathrm{X} 1)$ column oven temperature $\left(20-40^{\circ} \mathrm{C}\right),(\mathrm{X} 2)$ flow rate $(0.8-1.2 \mathrm{ml} / \mathrm{min}),(\mathrm{X} 3)$ acid concentration in aqueous phase $(0-2 \%),(\mathrm{X} 4)$ organic solvent percentage at the beginning $(40-50 \%)$, and (X5) at the end (50-60\%) of the gradient mobile phase, as well as (X6) ratio of methanol/acetonitrile at the beginning (1-4) and (X7) at the end (0-1) of gradient mobile phase. Responses of chromatographic analysis were resolution of mycotoxin peaks and HPLC run time. A central composite design (CCD) using response surface methodology (RSM) was then carried out for optimization of the most significant factors by multiple regression models for response variables. The proposed optimal method using $40^{\circ} \mathrm{C}$ oven temperature, $1 \mathrm{ml} / \mathrm{min}$ flow rate, $0.1 \%$ acetic acid concentration in aqueous phase, $41 \%$ organic phase (beginning), $60 \%$ organic phase (end), 1.92 ratio of methanol to acetonitrile (beginning) and 0.2 ratio (end) for $\mathrm{X} 1-\mathrm{X} 7$, respectively, showed good prediction ability between the experimental data and predictive values throughout the studied parameter space. Finally, the optimized method was validated by measuring the linearity, sensitivity, accuracy and precision parameters, and has been applied successfully to the analysis of spiked cereal samples.
\end{abstract}

Keyword: Aflatoxin; Ochratoxin A; Zearalenone; Simutaneous determination; HPLC. 